\author{
Marquette University \\ e-Publications@Marquette
}

School of Dentistry Faculty Research and

Publications

Dentistry, School of

2-2010

\title{
Senior Dental Students' Experience with Cariogram in a Pediatric Dentistry Clinic
}

Cesar Gonzalez

Marquette University, cesar.gonzalez@marquette.edu

Christopher Okunseri

Marquette University, christopher.okunseri@marquette.edu

Follow this and additional works at: https://epublications.marquette.edu/dentistry_fac

Part of the Dentistry Commons

\section{Recommended Citation}

Gonzalez, Cesar and Okunseri, Christopher, "Senior Dental Students' Experience with Cariogram in a Pediatric Dentistry Clinic" (2010). School of Dentistry Faculty Research and Publications. 235.

https://epublications.marquette.edu/dentistry_fac/235 


\title{
Senior Dental Students' Experience with Cariogram in a Pediatric Dentistry Clinic
}

\author{
Cesar D. Gonzalez, D.D.S., M.S.; Christopher Okunseri, B.D.S., M.Sc., F.F.D.R.C.S.I.
}

Abstract: The study objective was to assess predoctoral dental students' experience with a caries risk assessment computer program in the pediatric dentistry clinic at Marquette University School of Dentistry. In 2005, spring semester sophomore dental students (class of 2008) were introduced to the caries risk assessment computer program "Cariogram." The students received a fifty-minute lecture on caries risk assessment and a demonstration on how to use Cariogram in the clinic. After two years of clinical exposure to Cariogram, sixty-six out of eighty senior dental students completed an anonymous eleven-item questionnaire on their experience with the tool. Each item on the questionnaire was scored on a five-point Likert scale with the exception of two questions. Full- and part-time faculty members in the pediatric dentistry clinic were involved in teaching and supervising students in the use of Cariogram for caries risk assessment after their training and calibration. Forty-five percent of the students who participated in the study agreed that Cariogram was easy to understand, and 18 percent disagreed. Thirty-six percent felt that it was easy to apply, and 25 percent reported that it was useful in determining caries preventive procedures. The students reported that 60 percent of full-time and 33 percent of part-time faculty were knowledgeable about Cariogram use. A majority of the students felt that Cariogram was not easy to understand, and eighty-two percent of them reported that they would not be using Cariogram in their private offices. Future studies should explore reasons why students do not feel inclined to use Cariogram as a caries risk assessment tool in their private practices even after being exposed to the tool in dental school.

Dr. Gonzalez is Associate Professor and Director, Division of Pediatric Dentistry, Department of Developmental Sciences; and Dr. Okunseri is Associate Professor, Department of Clinical Services - both at Marquette University School of Dentistry. Direct correspondence and requests for reprints to Dr. Cesar D. Gonzalez, Department of Developmental Sciences, Room 356, Marquette University School of Dentistry, P.O. Box 1881, Milwaukee, WI 53201-1881; 414-288-6391 phone; 414-288-0765 fax; cesar.gonzalez@marquette.edu.

Keywords: Cariogram, children, risk assessment, dental students

Submitted for publication 4/23/09; accepted 10/23/09

$\mathrm{N}$ umerous caries risk assessment (CRA) models have been developed and implemented by dental institutions in Canada and the United States. A recent survey of Canadian and U.S. dental schools regarding the current status of teaching dental caries management found that 68 percent (forty-five out of sixty-six) included CRA in their clinical caries management curriculum. ${ }^{1}$ The education of predoctoral dental students in CRA is important because it is believed that it will encourage them as future dental practitioners to provide preventive and restorative care based on the best available evidence. In addition, it is important that students understand and embrace the concept of oral health promotion and the social determinants of oral health in the management of oral diseases.

In 2002, a caries risk assessment tool (CAT) was developed by the American Academy of Pediatric Dentistry (AAPD) to promote the understanding and application of pediatric caries risk assessment in clinical practice. $^{2}$ In 2003, caries management by risk assessment (CAMBRA) was developed by a consortium of dental-related organizations. ${ }^{3}$ This risk assessment tool is currently used in five California dental schools as well as in dental schools in Oregon, Washington, Arizona, and Nevada.

The caries risk assessment computer program "Cariogram" was developed at Malmö University in Sweden. ${ }^{4}$ Cariogram includes information about the multifactorial background of dental caries using a graphic model. It illustrates the interactions of various interrelated caries risk factors in a simple way, with caries risk expressed as the percent chance to avoid new caries. The computer program also illustrates the extent to which these factors affect the chance for the disease to occur. Cariogram evaluation is based on the input of data that includes past caries experience, diet, oral hygiene, use of fluoride, and results from saliva analyses (mutans streptococci, lactobacilli, saliva buffering capacity, and secretion rate). These factors are scored based on a predetermined scale and entered into the computer program. ${ }^{4}$ Based on a builtin formula, the program presents a pie chart in which bacteria appears as a red sector, diet as a dark blue sector, susceptibility-related factors as a light blue sector, and circumstances as a yellow sector (Figure 1). The four sectors take their share of the pie, and what is left appears as a green sector and represents 


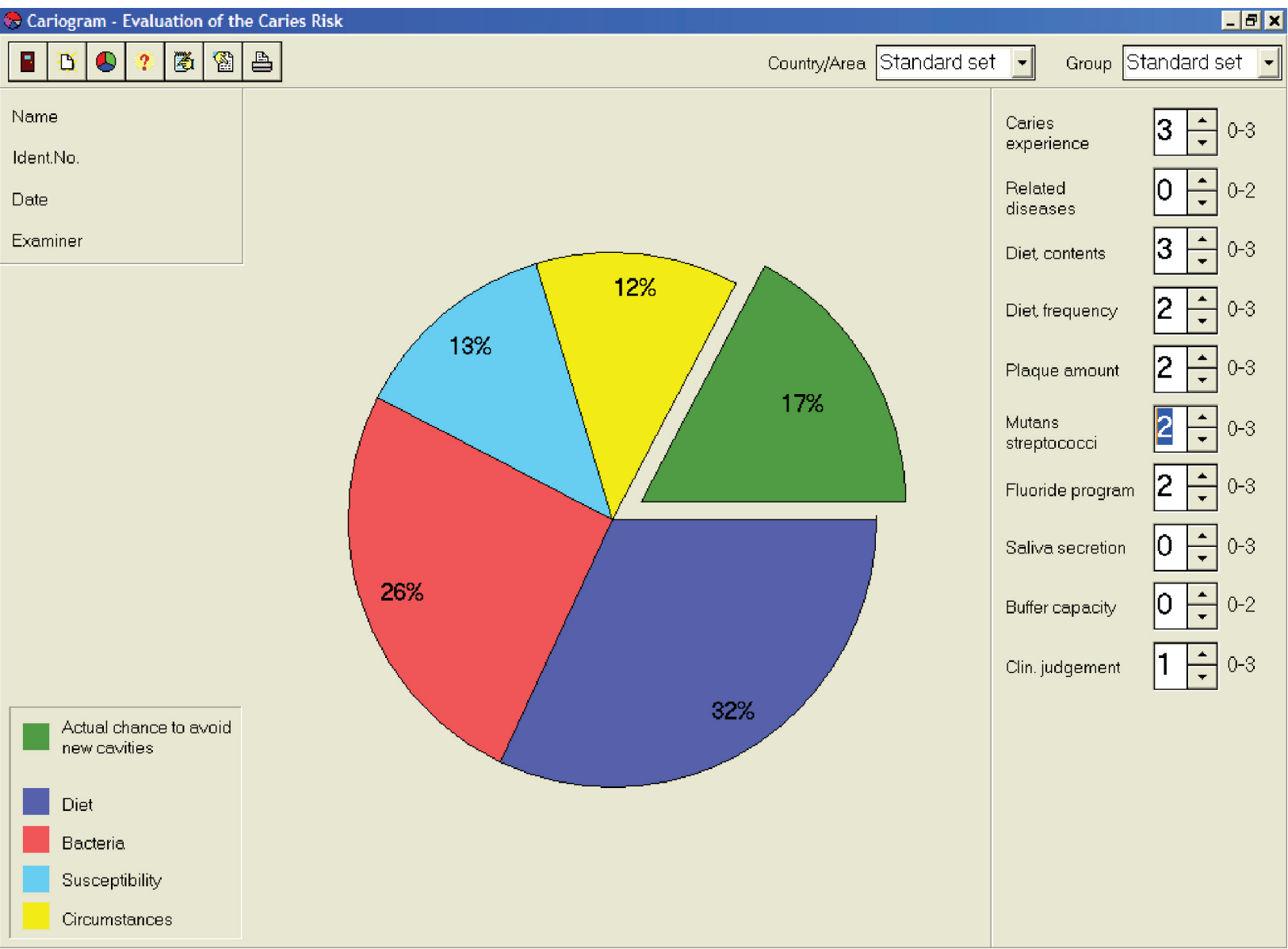

Figure 1. Example of a Cariogram pie chart for the evaluation of caries risk generated by axiUm at the pediatric dentistry clinic

the chance of avoiding caries. The dark blue sector "Diet" is based on a combination of diet contents and diet frequency. The red sector "Bacteria" is based on a combination of the amount of plaque and mutans streptococci. The light blue sector "Susceptibility" is based on a combination of fluoride ingestion, saliva secretion, and saliva buffer capacity. The yellow sector "Circumstances" is based on a combination of caries experience and related diseases. The green sector shows an estimation of the "chance of avoiding caries." The program generates an individualized report titled "preliminary interpretation and proposed measures," which includes therapeutic strategies for prevention and risk reduction.

Cariogram as a caries risk assessment tool has been validated in several clinical studies. ${ }^{5-15}$ Hänsel-
Petersson et al.'s study on elderly adults demonstrated success with Cariogram in predicting the extent of future caries. ${ }^{8}$ Holgerson et al. conducted a longitudinal study of ten- to eleven-year-old school children over two years and found that Cariogram predicted caries increment more accurately than any included single factor model. ${ }^{14}$ However, dental students' perception of this tool as used in the development of a treatment plan for a patient in an academic setting has not been evaluated and documented. Information on students' perceptions of a teaching tool such as the caries risk assessment is critical to its successful implementation in dental schools and its eventual use by dental practitioners in their private offices for patient care. The aim of this study was to evaluate senior dental students' experience with and perceptions of Cario- 
gram in the pediatric dentistry clinic at the Marquette University School of Dentistry.

\section{Methods}

In 2005, sophomore dental students (class of 2008) at Marquette University School of Dentistry (MUSoD) were introduced to Cariogram in the spring semester. The students received a fifty-minute lecture on caries risk assessment and a demonstration of Cariogram as part of the pediatric curriculum. The sophomore dental students completed a case-based written examination regarding their knowledge and application of Cariogram. The training and calibration exercise for full-time and part-time faculty was done by the program director as part of a pediatric dentistry meeting specifically designed for this purpose, with one hour dedicated to the presentation and one hour for questions.

At MUSoD, dental students are allowed to provide direct patient care for adults and children in their junior year. Junior and senior dental students are assigned to the pediatric dentistry clinic one halfsession every other week for their entire junior and senior years. When students are assigned patients, they are responsible for conducting initial examinations, treatment planning, and completing all treatments under the supervision of faculty. Faculty members routinely review Cariogram reports with students, and changes are made when appropriate along with explanations for modifying students' caries risk assessments. A preventive menu in accordance with risk status is explained to the patient's parents, and a hard copy is given to the parents at the end of the appointment.

After two years of sophomore students' clinical exposure to the use of Cariogram, sixty-six out of eighty senior dental students (Class of 2008) completed a one-page anonymous eleven-item questionnaire on their experience with the caries risk assessment tool (Table 1). The questions used for this survey are similar to those used in an article by Nainar and Straffon. ${ }^{17}$ To avoid any coercion by faculty, the questionnaires were administered after the completion of their pediatric dentistry clinical rotation and the award of course grades. The students who did not participate in this study were either out on other rotations or had excused absences from school on the day the study was conducted. To avoid having small cell counts and for ease in description of findings, the students' ratings of $5=$ strongly agree and $4=$ agree were combined into a single variable of agree. The ratings of $2=$ disagree and $1=$ strongly disagree were combined into a single variable of disagree; $3=$ neutral ratings were left intact. Descriptive statistics were performed on data collected using SPSS 15.5. This study was reviewed and approved by the Institutional Review Board at Marquette University.

Table 1. Questions used to evaluate the Cariogram model

Questions

Gender

The Cariogram risk assessment model was easy to understand.

Cariogram was simple to apply in the pediatric dentistry clinic (PDC).

Cariogram was useful in determining preventive procedures for children in the PDC.

The full-time faculty was knowledgeable in using Cariogram in the PDC.

The part-time faculty was knowledgeable in using Cariogram in the PDC.

On average, the faculty (part- and full-time) and I agreed on my rating of caries risk assessment using Cariogram on children in the PDC.

I would like to see Cariogram used in the adult clinic as well.

I will likely use Cariogram in my private practice to assess caries risk in children and/or adults.

I would likely use some form of caries risk assessment in my private practice to assess caries risk in children or adults.

Which of the following best describes your plans after dental school?
Answer Options

Female, Male

Strongly Agree, Agree, Neutral, Disagree, Strongly Disagree Strongly Agree, Agree, Neutral, Disagree, Strongly Disagree

Strongly Agree, Agree, Neutral, Disagree, Strongly Disagree

Strongly Agree, Agree, Neutral, Disagree, Strongly Disagree

Strongly Agree, Agree, Neutral, Disagree, Strongly Disagree

Strongly Agree, Agree, Neutral, Disagree, Strongly Disagree

Strongly Agree, Agree, Neutral, Disagree, Strongly Disagree

Strongly Agree, Agree, Neutral, Disagree, Strongly Disagree

Strongly Agree, Agree, Neutral, Disagree, Strongly Disagree

Private practice, community dental clinic, graduate program, other 


\section{Results}

Eighty-three percent (sixty-six out of eighty) of the senior dental students completed the survey. Males accounted for 52 percent of the respondents.

Table 2 shows the percentage of students responding to the questions directly related to the application of Cariogram in the pediatric dental clinic. On whether Cariogram was easy to understand, 45 percent of the senior dental students agreed that it was easy to understand, 37 percent were neutral, and 18 percent disagreed. On whether it was simple to apply, 36 percent felt it was, but an almost equal percentage reported neutral (30 percent) and disagree (34 percent). When assessing whether Cariogram was useful in determining preventive procedures for children in the clinic, only 25 percent reported that it was useful, and 40 percent did not think it accomplished that objective. When asked about the knowledge of full-time and part-time faculty regarding the use of Cariogram, the students reported that 60 percent of full-time and 33 percent of part-time faculty were knowledgeable about use of the program. On whether both the fulltime and part-time faculty agreed with the caries risk assessment produced by senior students after using Cariogram, 52 percent of the students reported that both agreed with the results.

When asked whether the students would like to see Cariogram implemented in the adult clinics, only 6 percent agreed while 84 percent disagreed. In addition, we asked whether students would use Cariogram in their private practices after graduation, and 82 percent reported that they would not use it.
However, when asked if they would use some kind of caries risk assessment for children and/or adults in their private practice, 52 percent of students responded that they would.

\section{Discussion}

Dental caries experience is concentrated in a segment of the pediatric population, with 80 percent of caries experienced in permanent teeth occurring in 25 percent of five- to seventeen-year-olds. ${ }^{4}$ This concentration of dental caries experience in a minority of children increases the urgency and need for the use of caries risk assessment in clinical practice. The pediatric dentistry clinic at Marquette University School of Dentistry had for two academic years (2003-04 and 2004-05) used a caries risk assessment tool developed by the American Academy of Pediatric Dentistry. ${ }^{2}$ At the start of the 2005-06 academic year, a decision was made to use Cariogram as the caries risk assessment tool in the clinic. The faculty recommended Cariogram because the program provides a graph that describes different risk factors and offers an interactive and educational experience to both students and patients/parents. This graph is also a basis for discussions about risk factors and preventive strategies with patients/parents.

During the students' pediatric dentistry clinical rotation, they are expected to schedule all new and recall patients based on caries risk assessment using Cariogram. On average, the senior students used Cariogram seventeen to nineteen times during the two years of their pediatric clinical rotation at

Table 2. Frequency distribution of dental students' response to their experience with Cariogram, by percentage of total responses

\begin{tabular}{|c|c|c|c|}
\hline Description & $\begin{array}{l}\text { Atrongly Agree/ } \\
\text { Agree }\end{array}$ & Neutral & $\begin{array}{c}\text { Strongly Disagree/ } \\
\text { Disagree }\end{array}$ \\
\hline Easy to understand & 45 & 37 & 18 \\
\hline Simple to apply & 36 & 30 & 34 \\
\hline Useful for determining preventive procedures & 25 & 34 & 40 \\
\hline Full-time faculty knowledgeable about Cariogram & 60 & 28 & 12 \\
\hline Part-time faculty knowledgeable about Cariogram & 33 & 40 & 27 \\
\hline Faculty agreed with my rating of caries risk using Cariogram & 52 & 36 & 12 \\
\hline Would like to see Cariogram used in adult clinic & 6 & 10 & 84 \\
\hline Will likely use Cariogram in my private practice & 6 & 12 & 82 \\
\hline Will likely use some form of caries risk assessment in my private practice & 52 & 18 & 30 \\
\hline
\end{tabular}


MUSoD. The caries risk output from Cariogram has four levels: very high risk, high risk, intermediate risk, and low risk. However, students are taught to use the standard three levels based on available evidence. Cariogram's very high risk and high risk are described as high risk (standard level 1), intermediate risk as moderate risk (standard level 2), and low risk as low risk (standard level 3). Based on the available evidence, the following recall schedules for caries risk assessment were used at the pediatric dentistry clinic: nine to twelve months for low-risk patients; six to nine months for moderate-risk patients; three to six months for high-risk patients. ${ }^{16}$ However, the majority of patients attending the pediatric dentistry clinic at MUSoD are on Medicaid, which covers only two examinations per year. This made it extremely difficult to fully implement the prescribed recall system on some occasions based on the caries risk schedule stated. For this reason, we are currently in the process of negotiating with Medicaid to allow for appropriate recall based on caries risk assessment of patients.

In our study, the percentage of students reporting that Cariogram was easy to understand was less than 50 percent. This result was somewhat surprising given that the students had been exposed to the tool for at least two years. However, it could also be a true reflection of students' lack of interest in using Cariogram as a caries risk assessment tool. Our finding is in contrast to the survey conducted by Nainar and Straffon at the University of Michigan, in which 86 percent of predoctoral dental students agreed that the AAPD's caries assessment tool (CAT) was easy to understand. ${ }^{17}$ In addition, 76 percent of the students surveyed by Nainar and Straffon reported that CAT was simple to apply, ${ }^{17}$ while only one-third of our study population agreed that Cariogram was simple to apply. Although both tools are designed to assess caries risk, the results observed suggest that students felt more comfortable using CAT than Cariogram. The reasons why students prefer one caries risk tool to another cannot be addressed by this study. However, future studies should be conducted involving multiple dental schools to better understand senior dental students' perceptions of the different caries risk assessment tools available.

The evidence for managing dental caries through surgical and nonsurgical approaches has led more dental schools to incorporate caries risk assessment tools/protocols into their dental curricula. Most dental schools require that faculty be knowledgeable, trained, and calibrated in the caries risk assessment tool used at their school. At our study location, fulland part-time faculty members participated in a training and calibration exercise with the program director before Cariogram was implemented on the pediatric dentistry clinic floor. In our study, 60 percent of the senior dental students surveyed agreed that full-time faculty were knowledgeable about Cariogram. One interpretation of this finding is that more work needs to be done to improve the knowledge base of fulltime faculty on the use of Cariogram before it can be completely embraced by students. In addition, only one-third of the students agreed that part-time faculty were knowledgeable about Cariogram, further reinforcing the need for improvement of the knowledge base of both full- and part-time faculty on the use of Cariogram. Another interpretation of our finding could be that Cariogram as a caries risk assessment tool is not particularly user-friendly contrary to views held by investigators before it was implemented at the clinic. Furthermore, slightly over 50 percent of the students reported that faculty agreed with their caries risk assessment using Cariogram. Findings from this study demonstrate the need for adequate consultation, training, calibration of full- and parttime faculty, and when possible conducting a pilottest with students before full implementation of Cariogram into the clinic.

In our study, 25 percent of the students agreed that Cariogram was useful for determining preventive procedures. This is in contrast to findings from Nainar and Straffon's study that reported 76 percent of the students found CAT useful for prescribing radiographs and 84 percent agreed that it was a useful tool for determining preventive procedures. ${ }^{17}$ While validation studies of Cariogram have described it as effective in categorizing children and the elderly, the practicality of using it in caries risk assessment in a large clinical setting like a dental school's pediatric dental clinic is called into question here based on findings from our study. The relatively low response by students to the usefulness of Cariogram for determining preventive procedures in this study could also suggest that not enough time was dedicated to teaching the dental students about it since only an hour lecture was provided to the sophomore students before entering the clinic as juniors.

The implementation of a practical caries risk assessment and management of caries as a disease in teaching and private practice environments are critical if we are to change from the traditional restorative mindset to a more preventive approach. Eighty-four percent of our respondents would not support the im- 
plementation of Cariogram in the adult clinic, and 82 percent said they were unlikely to implement this tool in their private practices. In addition, 52 percent of the respondents reported they would use some form of caries risk assessment in their private practice. These findings reinforce the difficulties in the implementation of a caries risk assessment tool into a teaching environment and/or private practice as reported by others. ${ }^{18-20}$ Doméjean-Orliaguet et al. conducted a retrospective study at the University of California, San Francisco (UCSF) to evaluate a caries risk assessment tool in an educational environment. ${ }^{18}$ The authors reported that while the content and usefulness of the caries risk assessment tool used at UCSF were validated, it also emphasized the difficulties of integrating such programs in an educational setting even with an extensive student didactic program and faculty training. Other studies have reported indirect evidence from dental claims data showing dentists' unwillingness to incorporate caries risk assessment strategies in their practices. ${ }^{19,20}$ Our findings require further investigation given the importance and value placed on providing evidence-based dental care, which includes caries risk assessment.

Our study should be considered in light of some limitations. First, the reported relatively low knowledge of part-time faculty in using Cariogram by students could create a potential bias in the minds of students about the usefulness and ease of use of the tool. Second, the non-inclusion of bacterial count of mutans streptococci and salivary flow rate in the implementation of the Cariogram tool could potentially lead to students' lack of interest in it. Third, the non-implementation of Cariogram in the adult clinics and community clinics where the senior dental students also manage patients could potentially account for some of their responses. However, our findings suggest a need for a more comprehensive educational model in dental institutions trying to incorporate caries risk assessment into their dental curriculum. Marquette University School of Dentistry is committed to the implementation of a caries risk assessment system for its pediatric and adult patients. It should be noted that the results of this study prompted the curriculum committee of MUSoD to implement the caries management by risk assessment (CAMBRA) ${ }^{3}$ as the main caries risk assessment tool in both the pediatric dentistry and the adult clinics beginning the 2009-10 academic year. However, Cariogram will continue to be used in both the adult and the pediatric dentistry clinics mostly as a teaching and discussion tool for students and parents. In conclusion, the majority of the students felt that Cariogram was not easy to understand and do not intend to use it in their private offices.

\section{Acknowledgment}

During this study, Christopher Okunseri was supported by Health Resources and Services Administration (HRSA) Maternal and Child Health Bureau grant R40MC08955.

\section{REFERENCES}

1. Brown JP. A new curriculum framework for clinical prevention and population health, with a review of clinical caries prevention teaching in U.S and Canadian schools. J Dent Educ 2007;71(5):572-8.

2. American Academy of Pediatric Dentistry. Policy on the use of a caries-risk assessment tool (CAT) for infants, children, and adolescents (reference manual 2002-03). Pediatr Dent 2002;24(7):15-7.

3. Featherstone JD, Adair SM, Anderson MH, Berkowitz RJ, Bird WF, Crall JJ, et al. Caries management by risk assessment: consensus statement, April 2002. J Calif Dent Assoc 2003;31(3):257-69.

4. Bratthall D, Petersson GH. Cariogram: a multifactorial risk assessment model for a multifactorial disease. Community Dent Oral Epidemiol 2005;33(4):256-64.

5. Hänsel-Petersson G, Carlsson P, Bratthall D. Caries risk assessment: a comparison between the computer program “cariogram," dental students and dental instructors. Eur J Dent Educ 1998;2:184-90.

6. Hänsel-Petersson G, Bratthall D. Caries risk assessment: a comparison between the computer program "cariogram," dental hygienists and dentists. Swed Dent J 2000;24(4):129-37.

7. Hänsel-Petersson G, Twetman S, Bratthall D. Evaluation of a computer program for caries risk assessment in schoolchildren. Caries Res 2002;36(5):327-40.

8. Hänsel-Petersson G, Fure S, Bratthall D. Evaluation of a computer-based caries risk assessment program in an elderly group of individuals. Acta Odontol Scand 2003;61(3):164-71.

9. Hänsel-Petersson G. Assessing caries risk using the cariogram model. Swed Dent J 2003;158(Suppl):1-65.

10. Alian AA, McNally ME, Fure S, Birkhed D. Assessment of caries risk in elderly patients using the cariogram model. J Can Dent Assoc 2006;72(5):459-63.

11. Zukanovic̀ A, Kobaslija S, Ganibegovic̀ M. Caries risk assessment in Bosnian children using cariogram computer model. Int Dent J 2007;57(3):177-83.

12. Stecksen-Blicks C, Holgerson PL, Twetman S. Caries risk profiles in two-year-old children from northern Sweden. Oral Health Prev Dent 2007;5(3):215-21.

13. Sonbul H, Al-Otaibi M, Birkhed D. Risk profile of adults with several dental restorations using the cariogram model. Acta Odontol Scand 2008;66(6):351-7. 
14. Holgerson PL, Twetman S, Stecksen-Blicks C. Validation of an age-modified caries risk assessment program (cariogram) in preschool children. Acta Odontol Scand 2009;67(2):106-12.

15. Al Mulla AH, Kharsa SA, Kjellberg H, Birkhed D. Caries risk profiles in orthodontic patients at follow-up using cariogram. Angle Orthod 2009;79(2):323-30.

16. Dental recall: recall interval between routine dental examinations. Clinical guideline 19. London: National Institute for Clinical Excellence, National Collaborating Centre for Acute Care, October 2004.
17. Nainar SM, Straffon LH. Predoctoral dental student evaluation of American Academy of Pediatric Dentistry's caries risk assessment tool. J Dent Educ 2006;70(3):292-5.

18. Doméjean-Orliaguet S, Gansky SA, Featherstone JD. Caries risk assessment in an educational environment. J Dent Educ 2006;70(12):1346-54.

19. Eklund S, Pittman, Heller K. Professionally applied topical fluoride and restorative care in insured children. J Public Health Dent 2000;60:33-8.

20. Bader J, Shugar D, White B, Rindal D. Evaluation of audit-based performance measures for dental care plans. J Public Health Dent 1999;59:150-7. 